\title{
Article
}

\section{Bloody Paperwork}

Algorithmic Governance and Control in UK Integrated Health and Social Care Settings

\author{
Guro Huby \\ Østfold University College
}

\author{
John Harries \\ University of Edinburgh
}

\begin{abstract}
This article is about paperwork: the work staff in UK integrated health and social care teams did to transform small transactions of everyday care work into big data, which in turn enabled the governance of complex service arrangements. This data-driven approach to governance, algorithmic governance, raises issues of agency and transparency. We address these issues by paying close attention to how care staff articulated their own understandings and apprehensions of the process. The article draws on a study of work roles in UK integrated health and social care teams providing support and follow up for older people and people with mental health problems. Digitised tools were used for the coordination and management of these teams. Staff described how the digitised documentation of care practices produced standardised representations of their work which poorly reflected the complexity of their everyday interactions with colleagues and clients/patients. There was a double-ness to these representations: on the one hand, they were malleable and open to negotiation, on the other they produced tangible consequences hardwired into the system of governance, transforming the work of care into an object outside of itself. In order to bring out the complexities in staff's accounts about paperwork, the article brings the Marxist analytic of alienation into conversation with Actor Network Theory (ANT) to suggest that overstating the hegemonic power of digital technologies risks itself becoming hegemonic. We advocate a nuanced and situated analysis of what digitised documentary practices consist of and what they do in different circumstances.
\end{abstract}

\section{Keywords}

algorithmic governance, datafication, alienation, Actor Network Theory, integrated health, social care public services 
Guro Huby E Fohn Harries - Bloody Paperwork

\section{Bloody Paperwork}

The title for this article stems from an interview with a psychiatric nurse, who we call Debbie, who was at the time working with a multidisciplinary Community Mental Health Team (CMHT) in the north of England. During the conversation one of the authors of this paper asked Debbie how she went about 'organising packages of care' for her clients. She paused for a second, sighed, and then said, 'oh it's a lot of bloody paperwork.'

That is not all she said. She went on at length about all the paperwork she had to do, how it was increasing and how displeased she and her colleagues were with the profusion of forms that had become part of the work of organising and delivering care. The amount of paperwork was measured in pages and time. The Care Programme Approach (CPA) brought with it '22 different pieces of paper.' One was a risk assessment form which had to be completed for everyone referred to the team. This form alone was ' 14 or 15 pages long' and took two to three hours to complete. Then there was the 'six monthly review of the packages of care', which meant more forms and more hours of writing, as well as letters to the General Practitioners (GPs) and so on and so on. Things had become so bad that she and her colleagues 'all dread[ed] doing assessments, not because of seeing the people, but all the paperwork it generates afterwards.' 'The biggest bane of the job', she sighed, 'is paperwork.'

They spoke about 'paperwork', but very little paper was involved. The forms that sparked Debbie and her colleagues' frustration were digital. They were uploaded and completed and returned by means of a computer. These forms were highly structured. Much of the information had to be squeezed into tick boxes which left little room for workers' own narratives about clients' problems and what they had done to solve them. The principles by which the forms were structured abstracted the complex, messy and highly individual work of everyday care into something else entirely: ordered, predictable and standardised.

It is this attitude towards the digital 'paperwork' associated with organising and delivering care that is the starting point for our discussion. Although we are locating our discussion in the growing field of critical algorithm studies analysing algorithmic governance and datafication, we will use, henceforward, the native term 'paperwork' without inverted commas, because this term captures the complexity of the phenomenon we are examining and provides analytic leverage for the purpose of this paper: for our respondents, paperwork was more than the forms and their inconvenience, it was the work of completing them that was at issue, how this affected their relationship to their day to day care work, and the ways in which emerging governance structures based on return of data mediated this relationship, in myriad ways.

In focusing on what staff in the health and social care settings told us about the work of paperwork we are addressing a blind spot in studies of new cultures of public sector administration. There is, as Kafka argues with reference to the work 
of historians, a tendency in sociological and anthropological studies of health and social care work to look 'through paperwork' (Kafka 2009, 341) and towards what appears as more significant discussions of bureaucracy, techniques of management, and forms of governance. Yet, the work of paperwork is intrinsic to bureaucracy, management and governance. Although moaning about paperwork is so commonplace to seem hardly worth noting, what staff have to say about paperwork is revealing of the different ways in which socially embedded techniques of datafication mediate care professionals' relationship with the work they do.

To be clear, not all paperwork was 'bloody' paperwork. The staff we spoke to agreed with Debbie that 'writing things in the notes' in order to share information within a multidisciplinary team was important for the coordination and follow up of care for individual clients. It was paperwork associated with a peculiar form of public-sector governance, which we analyse as 'algorithmic', that is the focus of this paper. Governance - algorithmic and otherwise - is socially embedded in specific ways and so produces specific effects and affects. What staff told us of their experiences of '(bloody) paperwork' provides, therefore, a perspective into contemporary aspects of public sector policy and management that is to some extent 'black-boxed'.

\section{Integration and Governance in Health and Social Care}

Our reflections on paperwork draw on material from a 2008-2009 study concerning the 'reconfiguration of social care roles' in integrated health and social care teams in Scotland, England and Wales (Huby et al. 2010). The material, although more than 10 years old, is a salient reminder of long term and ongoing dilemmas of the governance of public sector services. The UK policy on health and social care integration constitutes a governance regime with a mix of selfregulated coordination and hard-wired state control. Shifting policy contexts impact on the mix (Huby, Cook and Kirchoff 2018).

Health and social care integration, that is bringing together health and social care organisations in order to better support vulnerable people with complex needs, has been a core UK policy agenda since the 1970s (Woods 2001; Glasby 2006, 2017; Gov.UK 2014). This has been driven by a number of factors, including a rising proportion of the population living into older age often with frailty and comorbidity, the shift in morbidity patterns from short-term acute to long-term chronic conditions and relocation of patients with mental illness of various degrees of severity into the community. On the ground, integration often takes the form of multidisciplinary and co-located teams whose members have different professional and occupational backgrounds and are seconded from different sectors, local authority and National Health Service (NHS) being the most important ones. The team as a collective is responsible for the care and follow-up of clients on the team's list. This implies a reconfiguration or adjustment of professional and occupational roles in order to respond to clients' complex needs. 
Emerging governance arrangements set the parameters for this reconfiguration of roles. The integration agenda is enveloped in far-reaching policy changes relating to the organisation and governance of community-based long-term social care. Care management is a case in point. The Griffiths reforms of local authority social care in the 1990's (Griffiths 1988) did away with the one-to-one relationship between a worker and his or her client as the basis of community-based long-term social care. The one-to-one relationships were inimical to multidisciplinary care and to control of costs and budgets - because they left decisions to the professional judgement of individual care workers. Care professionals became care managers, whose role it was to work out a care plan, based on an 'objective' assessment of user needs, and submit this to the local authority department, which then commissioned the care. Implied in this move to a care management approach is a shift from specialised, professional to generic roles, with data return a key component.

The study concerned how staff in integrated teams for older people and people with mental health problems negotiated the division of work and responsibility between professions, occupational groups and services sectors in the name of 'holistic and person-centred' care, and against a backdrop of shifting governance arrangements. This article focuses on how paperwork, that is the work of transforming people and their situation into data which could be subsequently combined with more data to provide an intelligible surface for the operation of public sector governance, was implicated in these negotiations. A central point in our argument is that a shifting ground of regulation rendered the power of the algorithms unstable.

The term 'governance' has a long history (Bevir 2008). Our take on governance is situated in key developments in the public service administration associated with political and economic liberalisation from the 1980's onwards. The nature of these reforms was set out in a classic text by Osborne and Gaebler (1992) in which they called for a shift from centralised state hierarchies towards a decentralized and innovative state fit to address increasingly complex problems in rapidly changing environments. Rhodes (1994) associated this trend with a 'hollowing out of the state' through a process that Ysa, Albareda and Forberger (2014, 9) describe as power shifting 'upwards, sideways and downwards' from national governments to a range of public, private, and voluntary actors. Governments became one actor among many in networks that collaborate to implement public sector policy. In this context, a tension arises between the state's roles as a collaborator and as a protector of the public purse strings. Cost effectiveness - increased productivity and 'quality' with the same or less resources - is a cornerstone of these new policies.

These developments and the ensuing dilemmas have been captured in a substantial literature concerning New Public Management or NPM (Hood 1991, 1995; Dunleavy and Hood 1994). NPM is a mixed bag, but we highlight three key features. The first is the ambition to devolve responsibility for the running of 
public services to networks of partners at local levels. The second is the introduction of private sector management techniques centring on quality performance and cost control. The third is the development of regimes of control from the centre through performance management, which makes local services and service networks responsible for the monitoring of their performance against nationally established targets.

There is a question as to whether NPM and PA (the 30's and 40's Public Administration hierarchies as instruments of government) denote radically different paradigms or are shorthand terms which miss the complexity of a rapidly changing picture; however, many writers (Le Grand 2003; McLaughlin, Ferlie and Osborne 2002) stress that several elements of the old PA and the new NPM exist simultaneously. Osborne $(2010,1)$ circumvents the question of paradigms and places PA and NPM as regimes within the overall field of 'public policy implementation and public service delivery', each with core elements, but with overlapping features. He goes on to add another acronym, NPG, or New Public Governance and to describe NPM as only one (passing) stage in a longer-term development from unitary state-run public service hierarchies to networks of actors co-operating in public sector delivery. NPG recognises that public service provision is increasingly accomplished through such networks whose performance defies central regulation and monitoring; rather, the role of the state must be to facilitate the self-regulation of these networks through relational contracts of various degrees of formality, from formal contracts of service, to norms and expectations embedded in roles, importantly management roles.

The integrated services we studied sat square in the middle of a central NPG problematic, namely central control of dispersed and complex networks of services. Cooperation between actors from public, private and voluntary sectors, health and social care, working together to address local challenges with local resources and knowledge is a key element of the integration agenda. However, this agenda carries with it organisational challenges, with workers of 'integrated' services linking into two or more different 'parent' organisations, in our case chiefly the National Health Service (NHS) and Local Authority run social care services. Coordination of work between these services and their day-to-day management is thus a complex affair, involving several layers and departments within two different organisations both ultimately accountable for the implementation of government policy.

The paperwork in which staff we met in our study engaged was a key component of governance of this complexity. Power (1997) argues that 'audit', which used to mean a way of organising accounts of public and private income and expenditure for oversight and transparency, came to expand its function and shift its meaning. Audit became the documentation not only of financial transactions, but the translation of behaviour and transactions between people into predetermined formats that constitute an intelligible surface which allows for the arm's-length management and control. The development of audit technologies is part of, and 
at times drives, shifts of power between levels of government and the dispersal of decision-making power between actors, human and digital. Paperwork has, thus, grown in importance and become a central feature of, if not an actor in its own right, in the landscape of integrated health and social care.

The changing significance of paperwork in the context of emerging 'audit cultures' (Strathern 1996; Shore and Wright 2015), particularly to governance of higher education and health and social care, has received a fair amount of academic attention, much of it critical. Working in a tradition of scholarship which can be traced back to Walter Benjamin, Martin Heidegger and, more ambivalently, Max Weber, this critique has focused on the baleful effects of technologies of managerialism and modernist visions of technocratic utopia achieved through the smooth and rational functioning of bureaucratic machines fuelled by flows of information (cf. Power 2003; Tsoukas 1997; Shore and Wright 1999; Graeber 2015). Suggesting another perspective, Paul Du Gay (2000, 2005) and, in the context of health care management, Stefan Timmermans and Rene Almeling, argue for a more even-handed and situated appreciation of the techniques of 'objectification, commodification and standardization' (Timmerman and Almeling 2009, 21) which inhere in audit cultures. Ultimately, as Du Gay suggests, "the mere fact of bureaucratization tells us comparatively little about the concrete directions in which it operates in any given context', and so 'it is pointless to apply global moral judgements to bureaucratic conduct' (Du Gay 2000, 5). Similarly, Timmermans and Almeling call for a more 'descriptive approach' to the study of bureaucratic processes, one which is 'based on the recognition that neither actors nor consequences can be assumed a priori, but must be empirically established in all their intended, contradictory, and unintended consequences' (Timmermans and Almeling 2009, 26). Our study mines both perspectives in order to bring out the complexities of algorithmic governance.

\section{Algorithmic Governance, Integration, and the Work of Datafication}

Integration of public services is often quite a prosaic process. On the ground it was, at the time of our study, a matter of sharing buildings, offices and information and finding practical, everyday ways of collaborating to organise and deliver care to people with complex needs. Underpinning these forms of collaboration are, however, ambitions to transform the governance of public services so that what was once two separate bureaucratic domains became one administrative entity. These ambitions were mostly only partially realised, a zipper zipped halfway up as a manager of a rural mental health service in Scotland described it to one of the authors of this study (Cook and Harries 2014), giving rise to a proliferation of hybrid administrative forms. Central to these ambitions, however, was a harmonisation of the ways in which people were made into data and, in being made into data, became subjects of integrated governance that centred on a holistic and quantifiable appreciation of complex care needs. 
The aspiration to reintegrate public services so as to enable a more flexible, person-centred approach to care provision is embedded in theorisations of 'digital era governance' which, it is argued, holds the promise of 'putting back together many of the elements that NPM separated out into discrete corporate hierarchies' (Dunleavy et al. 2006, 480) and 'providing holistic services for citizens' by 'implementing thoroughgoing digital changes in administration' (Margetts and Dunleavy 2013, 1). What is offered is a vision of a shift towards a 'needs based holism' enabled by digital technologies in which the subject of care is no longer variously constituted within balkanised regimes of public service provision and governance. Rather, 'agile and resilient governmental structures' (Margetts and Dunleavy 2013, 6) are responsive to forms of subjectification where the constitution of care needs, ideally, devolves onto a digitally empowered citizenry.

At the time of our study, this vision was still a distant one. For the most part, and often to the frustration those working in 'integrated' teams, systems of digital administration and governance were still divided between the NHS and Local Authorities. Again, from the perspective of those 'at the coal-face', the reality of this division was quite prosaic. It was a matter of two different filing systems, which were made one by the use of rubber bands. Or different data entry and information management systems which did not 'talk' to each other and were only accessible by those employed either by the NHS or the Local Authority, a barrier that only could be overcome through informal circuits of communication within co-located care teams.

Nonetheless, even if visions of 'Digital Era Governance' were somewhat utopian, the desire to shift the organisation of services towards a more 'needs-based' and 'person-centred' focus that addressed the complex care requirements of the whole individual did inform the culture of paperwork in the integrated care teams studied back in 2008 and 2009. A case in point is the paperwork generated by 'Care Programme Approach' (CPA) that Debbie bemoans in the introduction. The CPA emerged in the early 1990s as part of more general moves to shift the balance of care for those living with sometimes severe mental health conditions away from the hospital and into the community. It was recognised that an effective support of this client group would require the coordination of both health and social care services, and this was very much contingent on a whole-systems approach to 'case management' centred around the complex and interdependent care needs of the individual (cf. Kingdom 1994; Simpson et al. 2003; Goodwin and Lawton-Smith 2010). Ideally, care management and the CPA was envisioned as 'a patient-led system that is designed to promote individual choices concerning the how, what and where of care and meet an individual's holistic needs through multi-professional assessment and active care co-ordination' (Goodwin and Lawton-Smith 2010, 3).

Underpinning and enabling the CPA were processes of standardized 'needs assessment', which would form the basis of the organisation and provision of health and social care to the individual and, at the same time allow for the 
effective coordination and allocation of resources based on data concerning the needs of local and national populations. The benefits of standardised processes of needs assessment, perceived or actual (cf. Lockwood and Marshall 1999), in both enabling a 'needs-led' approach to care and the coordination of health and social care governance is, in part, what gave rise to the proliferation of the peculiar form of paperwork that Debbie and other people we interviewed describe. The fact that this was 'bloody paperwork' suggests that something has perhaps gone wrong. Despite the aspirations to a more person-centred, needs-based approach, the CPA linked into governance techniques emphasising 'targets, standards, performance measures and financial incentives' (Simpson et al., 2003, 496). The result was a proliferation of a form of managerialism which many health and social care workers found oppressive because it took them away from the 'realities' of care work.

Visions of the 'Digital Era Governance' of public services are an instance of what been labelled 'algorithmic governance'. Broadly, algorithmic governance is enabled by developments in the capacity of digital technologies to store and analyse many bits of information so as to allow for the more effective administration of social life. König describes it as follows,

The emergence of algorithmic governance is tied to advances in digital technologies particularly since the 1990s, which have massively enhanced the capacities for information-based steering of activities and dealing with complex coordination problems. The explosion in the abilities to generate, transfer, store, and process information has made possible forms of networked interaction characterized by a co-presence of manifold entities which can dynamically adjust their behaviors. Moreover, the massive amounts of fine-grained information about distributed entities allows for finding patterns in their behaviors and interactions and to produce insights that can be used for the purpose of better understanding and ultimately coordinating these behaviors (König 2020, 496).

This 'tying' of transformations of governance to advances in digital technologies suggests a degree of techno-determinism, but, as Katzenbach and Ulbricht remind us, scholars concerned with algorithmic governance 'complicate this techno-determinist picture by asserting the high relevance of algorithms ... yet highlighting the economic, cultural and political contexts that both shape the design of algorithms as well as accommodate their operation' (Katzenbach and Ulbricht 2019,3). As Seaver suggests, algorithms are 'intrinsically cultural' and as such should be approached ethnographically 'as part of culture, constituted not only by rational, procedures but by institutions, people, intersecting contexts, and the rough-and-ready sensemaking that obtains in ordinary cultural life' (Seaver 2017, 10). 
It is this 'rough-and-ready sensemaking' amongst those working in integrated teams that is both the substance and subject of this paper. In addressing attitudes towards paperwork, we are focusing on what people made of processes of datafication, which are intrinsic to the very possibility of algorithmic governance. Datafication 'refers to taking information about all things under the sun including ones we never used to think of as information at all [...] and transforming it into a data format to make it quantified' (Mayer-Schönberger and Cukier 2017, 15). While, as Kalpokas critically notes, promoters of 'algorithmic governance' suggest that 'big data' allows for an 'un-mediated access to the worldas-it-is in all its multiplicity and complexity' (Kalpokas 2019, 13), in reality 'data do not naturally exist, but only emerge through a process of abstraction: something is taken from forms and processes, something which was not already there in discrete form before' (Mejias and Couldry 2019, 2).

In addressing paperwork as a process of datafication to allow algorithmic forms of governance in public services, we are, therefore, addressing the work of abstraction as a peculiar form of translation by which people and processes become quantitative data. Our emphasis is particularly on paperwork. For people and processes to become abstracted as data requires someone, and that someone included Debbie and many others we interviewed, to undertake this work of datafication by completing risk assessment forms, carers assessment forms and a myriad of other bits of paperwork that had become intrinsic to the very possibility of organising and providing health and social care.

\section{Studying Paperwork in a Health and Social Care System 'Half Zipped Up'}

We did not set out to study paperwork. Our study concerned ways in which staff in integrated teams managed and negotiated professional and occupational roles to meet clients' complex care needs. Paperwork as an intrinsic part of organisation and delivery of care emerged as a key issue in the course of the project. The research involved interviewing a total of 120 staff and managers in eight integrated health and social care teams, four of which were Community Mental Health Teams (CMHTs), providing care and support for people with mental illnesses, and four of which were teams providing and coordinating care and support for the elderly (OPT), in England and Scotland. We interviewed a cross section of staff: nurses, social workers, support staff, physiotherapists, occupational therapists. We spoke to team managers. Interviews were open ended and invited discussions of respondent's position and role within the team, the work (s)he did, how work was divided up between team members, relationships within the team and between the team and the wider integrated organisational landscape. We asked respondents to tell us about ways in which their work had changed over time, and what they saw as driving those changes. Interviews lasted between 30 and 90 minutes and were transcribed. The data management software NVIVO was used to organise and analyse the material. 
Analysis proceeded through a combination of open and closed coding. A team of 3 interviewers first developed a coding frame in order to establish broad themes within the data related to the negotiation of roles within the teams, e.g., 'doing and organising care', 'doing management', 'change', 'decision-making', 'relationships', 'making information'. Interviews were then coded to these broad themes. We then interrogated each theme to identify specific instances and proceeded by a process of inductive and deductive constant comparison to explore ways in which instances articulated across different settings and individual interviews in those settings.

The theme 'making information' stood out as significant and our interest was caught by the native expression (bloody) paperwork. The way the word was used condensed complexities of care work in a shifting governance context. We saw that the work of completing and returning the forms, the relationships, both human and digital, in which the work was embedded, and the products of this work were central to the work staff and managers did to make things 'work' in a half zipped up system. Moreover, in talking about paperwork, staff also marked out their place in the shifting occupational landscape where making things work implied negotiation and contesting of roles.

Handling the complexity of the material brought up by the term paperwork was a challenge. Much brought out the restricting aspects of paperwork Debbie so passionately bemoaned and played into a literature of 'governance' as an instrument of indirect power in a Foucauldian tradition. However, examples also abounded of how paperwork could bring people together to find solutions to problems caused by the same governance regime. Structuring our findings in lists of 'controlling aspects of paperwork' versus 'liberating aspects' only got us so far. We needed an analytical strategy that could bring out the dynamic role of paperwork. Our solution was to examine our material from two perspectives, grounded in two different theoretical traditions. A lens from the tradition of critique of bureaucracy centring on Marxist perspectives to alienation brings 'bloody' paperwork's distorting effects into view, whilst a perspective from Actor Network Theory (ANT) (Latour 2007) helps us see paperwork as a facilitating factor in making things 'work'. Bringing these two traditions into conversation produces no clear conclusions. However, it allows us to suggest that 'paperwork' could be both 'bloody' and facilitating, and to also begin exploring factors behind this transformation.

The decision to draw on these two traditions is pragmatic. In different ways the Marxist tradition of critique, with its focus on the exploitative social relations grounded in the organisation of labour, and the Latourian analytic, with its emphasis on understanding the fashioning of social networks through an attentiveness to everyday activities, provides a theoretical vocabulary with which to articulate the complex, and sometimes contradictory, effects of paperwork within integrated health and social care teams. It has been suggested that these two theoretical traditions share some common concerns, in particular a broadly 
materialist appreciation that an understanding of human social organisation is indivisible from the work by which these organisational forms come into being and are stabilised and reproduced through time (cf. Sayes 2017). Some have also argued that Actor Network Theory's recognition of objects as 'actors' participating in the generation of organisational forms may be brought into productive conversation with Marx's theorisation of the fetishism of commodities (Hornborg 2014). White (2013) however points out that Latour takes a robustly anti-fetishist approach, advocating a 'cultivation of a stubbornly realist attitude' (Latour 2004, 231), which avoids the reductive materialism underpinning a Marxist informed critique.

It is this advocacy of a rigorous and renewed empiricism in contrast to 'hermeneutics of suspicion' (Felski 2011, 574; White 2013, 667-668) that sets Actor Network Theory apart from the Marxist and allied forms of critique. In some ways this distinction between critical diagnostic of social formations, including their effects on the human spirit as it is expressed and cultivated in and through creative labour, and a more careful, empirical, description of how these formations come into being, can be found in the recent discussions of bureaucracy and technologies of audit to which we have referred earlier. On the one hand, Graeber (2012) and Shore and Wright (1999; 2015), drawing inspiration from a Foucauldian conceptualisation of 'power' and the indivisibility of power from the techniques which allow for its exercise, indulge in a form of critique which Latour (2015) suggests has 'run out of steam.' In contrast, Du Gay as well as Timmermans and Almeling, in a manner quite similar to Latour's anti-critique (cf. Noys 2014) suggest that any appreciation of the workings of bureaucracy begins in a close attentiveness to 'facts' of situation and how, indeed, facts emerge and gain their quality of facticity, though, for example, the work of datafication. As Du Gay argues, 'the more grey, meticulous and patiently documentary one's descriptive and analytic practice is ... the more difficult it is to maintain a general, critical opposition to "bureaucracy" (Du Gay 2005, 3). Of course, it is precisely this enervating of social critique that some find frustrating about the appeal to empirical realism, both in reference to Actor Network Theory and more generally. Whittle and Spicer suggest that, in spite of its critical potential and posturing, in practice Actor Network Theory tends toward 'an ontologically realist, epistemologically positivist and politically conservative account of organising' and therefore fails 'to contribute to the development of critical approaches to organization' (Whittle and Spicer 2008, 623). For the purpose of our paper, however, Actor Network Theory brings out an empirically grounded appreciation of how organisations emerge and transform, an appreciation which encompasses nonhuman actors. This is central for understanding the constitution of integrated health and social care teams and the role of paperwork in facilitating the coordination of care delivery and management. In contrast, the Marxist tradition of critical materialism and, in particular, the notion of alienation as it is articulated within that theoretical project, allows us to better understand and diagnose how it is that paperwork, its potential to enable the coordination of care notwithstanding, may become 'bloody paperwork'. 
Accordingly, in the following we will first present paperwork's alienating effects, and then discuss our material from an ANT perspective to examine how paperwork could enable the work of integration. In conclusion, we discuss some of the implications of our analysis for practice, politics and research of algorithmic governance and datafication.

\section{'Paperwork' as Alienation}

The notion of alienation has been most famously formulated in Marx's 1844 on manuscript 'on alienated labour' (1983, 131-152), giving rise to a series of sociological critiques of the baleful effects of industrial capitalism on wagelabourers, particularly in 1960s and 1970s (for a review of this literature see Erikson 1986). Pearlin (1962) studied alienation among nurses in an American hospital. After somewhat falling out of fashion as an analytical concept, alienation has enjoyed something of a minor revival of late, including among those who seek to describe the unhappy condition of health and social care professionals in the context of increasing managerialism and data-hungry forms of governance. Iliffe and Manthorpe $(2019,370)$ refer to the 'unexpected return of alienation' when considering 'job dissatisfaction, burnout and work estrangement in the NHS', while there have been recent empirical studies assessing the degree to which healthcare professionals feel disempowered and self-estranged by their conditions of work (Özer et al. 2019; Kartal 2018)

We want to return to a Marxist theorisation of alienation because, we argue, it puts emphasis on process and the 'direct relationship between the worker and production' (Marx 1983 [1844], 135), rather than mood. One weakness of the 1960 's studies of organisational alienation, as well as of the current use of the term, is that it refers to a kind of prevailing subjective disposition that may, or may not, be the effect of more objective social conditions. Pearlin, for example, defines alienation as 'subjectively experienced powerlessness' (1962: 314), while Iliffe and Manthorpe suggest that it is the 'feeling' that work is 'meaningless ... that defines alienation as a unidimensional construct of estrangement' (2019: 372). Reading through the accounts of those we interviewed, however, it is clear that they are not simply describing their mood (although there was much talk of this as well), they were describing their practical relationship with the work they did as it was constituted in the very doing of that work.

For Marx, the notion of alienation proceeds from 'an economic, contemporary fact':

That fact expresses nothing more but this: the object which labour produces - the product of labour - confronts it as alien being, as a power independent of the producer. The product of labour is labour embodied and made material in a thing; the objectification of labour. The realisation of labour is its objectification. Within political economy, this realisation 
appears as the loss of reality of the worker, objectification appears as the loss of the object and bondage to it; appropriation appears as alienation, as externalisation (1983 [1844]: 133).

The economic facts in the mid-19th century may be different from what they are now and the work of a multidisciplinary team managing and providing care in the community is quite different from that of the Manchester factory workers producing cotton textiles. But perhaps these differences can be overstated. For one thing, the people in the teams we studied did things. Much of what they did may have been 'knowledge work' (cf. Quinlan 2009), that is the work of creating, transferring and applying knowledge concerning a given client's situation, but, as those we talked to made clear to us, this work was inalienable from the ongoing and unfolding work of relating to the clients as individuals socially and emotionally.

We identified two issues in the descriptions of paperwork as alienating. One was that it did not adequately capture, describe or represent the 'reality' of the user's situation and the interactions between care worker and user to manage the situation. Paperwork thus removed the worker and his or her clients from the day to day lived reality of the care work and transformed, 'objectified' to recall the quote from Marx, this reality into something else. A second and related issue was that the work staff did to translate their everyday work into standardised formats of paperwork distorted their day-to-day care work and could come back at them in the form of sanctions hard-wired into the structures of the paperwork itself.

One main problem with paperwork was 'paperwork for paperwork's own sake', which did not adequately represent the reality of care work. Janet, a social worker in a CMHT in Scotland, commented on the local social service assessment form told us,

as a shared assessment tool, there're obviously limitations, because anything that's designed by a committee becomes vast and unmanageable. So, you have 19 pages to kind of tick boxes and then kind of bits for comment. (...) With people with mental health problems, there's a whole bit about walking. Do you need a walking stick? Well fair enough, they sometimes do, but it's not the focus of the work. (...) They have mobility problems, but it's not to do with being able to physically walk. They can't use buses because they're too scared of people. So, you have to write big, long screeds, and I think it's one of those things where it would have been maybe a better model to look at having a really simple care assessment with specialist modules for physical disability, mental health and other areas. 
The problem with these standardised forms is that they produced a curious mixture of both excess and lack of information. In Janet's case, the form at once asked her to return information that was not relevant and also deprived her of the possibilities to describe exactly what the users' mobility problems were and how she could go about helping to solve them. The work of 'paperwork for the sake of paperwork' was separate from the care work itself, creating a surface of signification unrelated to the messy reality of the care work. This surface reality was made up of numbers and tick boxes, of paperwork completed and forms filled in, which constituted a domain abstracted from the 'real' human process of caring.

A second issue related to 'paperwork for paperwork's own sake' was the ways in which the requirements of the paperwork could structure the care work in a manner that staff considered irrelevant to the purpose of their work. The work became about walking sticks, rather than the anxiety that prevented a person taking the bus. Moreover, sanctions were hard-wired into the structure of the paperwork itself, which held staff to account for the work of empty signification quite unrelated to the actual care work they did.

An Occupational Therapist and leader of a team organising and delivering care for older people in Scotland explained how in significant ways work only existed if it was entered into a form. This respondent took pride in the work she did with unpaid carers. However, because she had omitted a piece of paperwork, her work did in a sense not exist. Moreover, she was sanctioned for the omission, although, in her opinion, her work, that is the work she did with people in the community, was of high quality:

Because at the end of the day, there's this assumption that if you haven't written it in those boxes you haven't done it as well. I actually had identified these needs of these carers and actually we've got her, the carer, another worker, their own worker, who was going round every week, to discuss the client and how to manage the situation. And these carers happened to go to a carers' organisation and someone at the carers' organisation said, 'have you had a carer's assessment? Where's your care plan?' And they said, 'oh we haven't had one done.' And so, we got this letter saying you've got to do a carer's assessment. This is illegal, all this stuff. So, she wants us to fill this form in. (...) And I wrote a letter back, no I rang her up, and I said, 'I've done the assessment', and she said, 'well where's the evidence?' And because I hadn't written it on this form it didn't exist. But if you read my daily notes, it was crammed from top to bottom with references to carers. 
Janet, the social worker in a Scottish CMHT, made a similar point about how paperwork seemed to be valued over and above the work of organising and providing care to those living in the community with complex conditions:

I picked up a form, a folder once, it happened to be a social worker, and the folder was so neat, so tidy. All the CPA was filled out properly. Every box was filled, and every box was ticked, but I knew this individual hadn't done any work at all with the patient, and his value judgement was absolutely crap. But the paperwork was fantastic. I mean, I wish all my files looked like that, whereas my files have got big sticking out bits of paper, and all the paperwork is not done. (...) We have a naughty boys - naughty girls list. It comes out each month, who hasn't done the CPA. And I often think your better nurses and your better social workers are the ones who keep appearing on the naughty boys or girls list.

These comments portray paperwork as alienating, in the way it cuts people off from their ongoing relationships to their day-to-day work and its products. 'Paperwork' can become a 'thing' which exists outside of these relationships. At best, it appears as a waste of time and irrelevant nuisance, at worst it has real power to shape and distort their everyday work, in ways which staff are powerless to resist.

\section{The Instability of Algorithms}

However, the 'thingness' of paperwork as an external force could collapse and transform into something else, almost by a flick of the wrist, as illustrated by a piece of real ethnography carried out by one of the authors who was invited to one of a series of regular meetings devoted to the redesign of community mental health services in the area under study, particularly in light of the projected closure of hospital beds.

Various managers from the Community Health Partnership (bringing together primary care NHS services and local authority services) and the Local Authority were there, as were a few health professionals. Service redesign was predicated on some insight into the present nature of the service and part of the meeting was devoted to trying to bring into visibility what the staff in the CMHTs were doing. 'Activity data' was circulated in the form of a 'monthly contacts report', which showed how many people each GMHT had seen over the preceding month. The contact report, we were told, had been generated by entries onto the PIMs system, a computer-based Patient Information System, on to which staff were meant to $\log$ all contacts they had with service users. 
It took no more than a few minutes for this data to melt away to nothing. It was noted that not all teams were entering all their contacts and one team had entered no contacts at all. Moreover, even if the staff had conscientiously entered each and every contact, this would still be insufficient as an 'activity report' since, as a nurse manager argued, the 'cases' varied widely, and activities associated with the care of these people varied accordingly. An accountancy of care that assumed an equivalence of 'cases' was, in her words, therefore 'meaningless'. After this, there was talk about how to overcome the apparent inadequacy of the 'activity data' before the meeting moved on to reports from 'consultation meetings', arranging a much-anticipated service development event and producing a newsletter for service users.

We note three things about this episode. The first is that the activity reports were circulated in the first place, handed around the table as neat and complete tables of figures. Despite the seemingly widely appreciated inadequacy of techniques of data-generation, they nonetheless began their short life in the meeting as reality: a surface of visibility upon which informed decisions concerning the future of the service could be made. The second is how quickly the apparent transparency of this surface of visibility became muddy, opaque and finally, became no more than a bunch of numbers on paper, whose orderly appearance betrayed nothing more than their representational inadequacy. The third is that the data produced by the work of datafication was transformed from hard reality to a bunch of numbers without significance in a conversation between people with pre-existing relationships with the day-to-day realities of work in the teams, built up over time and through regular engagement.

\section{Paperwork as Facilitating - A Perspective from ANT}

We now turn to the proposition that paperwork may facilitate the work of integrated care. This perspective presents paperwork as a tool that could help staff and their managers navigate the new reality of care work in integrated settings, but only if it became part of a conversation between, and entered into a relationship with, people who were close to the work of caring and paperwork and producing the products - care and data - in the first place.

A perspective from ANT proposed by Bruno Latour (2007) brings out the unpredictable nature of human-material entanglements (Orlikowski 2007) we create in engagements with the environment. His text is also a critique of social science methods used to investigate such entanglements and their effects. He suggests doing away with abstractions that are treated as entities - for example algorithmic governance and its totalising and alienating impact on day-to-day care work - that imbue an idea with a life and solidity of its own. This solidity is bolstered by social science conventions from Weber, via Foucault, and to an anthropologist's experience of grappling with the care system of today's UK, and it has its uses. However, it masks the nature of digital tools as being at once a 'thing', an activity and a process which may draw us into places we did not expect 
or want to be, but which can also be made to take us to places we want to go. Moreover, the very solidity of the idea of paperwork as totalising runs rather roughshod over the complexities of agency and takes away the possibility of people doing the paperwork to shape the way paperwork impacts on their day-today work. It makes them instruments of their own suppression.

Doing away with predefinitions would leave us free to follow the myriad of transactions that constitute the phenomenon of paperwork in health and social care, looking for what these transactions produce by way of human-digital entanglements in different contexts. Although our study did not follow an ANT methodology, an ANT approach to analysis brings out agency as a puzzle with considerable analytical and theoretical leverage. This approach recognises that people and objects - computers, forms, algorithms alike - can be 'participants in the course of action' (Latour 2007, 70), with transformative powers derived from a position in a network of both human and material actants. The way 'the CPA' can become a punishing force through the 'naughty boys and girls lists' that managers are obliged to distribute within the team, is a case in point. However, the status of actant is not given. Whether and how the lists are acted upon depends on the dynamics of a particular team, and its position in a wider organisational service setting. It all depends on context, and context is shifting and dislocal, and, as Latour argues, if action is dislocal, it does not pertain to any specific site; it is distributed, variegated, multiple, dislocated and remains a puzzle for the analyst as well as for the actors' $(2007,60)$.

Dislocal action was everywhere in the integrated service settings we studied. The chains of cause and effect that linked a worker's actions to a result had grown in size and complexity, as exemplified in the arrangements of care management described above. What once could be accomplished through a phone call or a conversation now required the intermediary of several forms that carried a number of functions, not all of which delivered the promised result in terms of a seamless and democratised provision of care.

Paperwork had, therefore, become an integral part of the multidisciplinary work in integrated teams. This work depended on members of different professions trading skills and responsibilities in order to provide care that centred on clients' needs. Negotiations between different professions concerning the maintenance of professional boundaries and protecting status and identity could get in the way (Nancarrow and Borthwick, 2005). An important tension that runs through our material, is one of professional rivalry between nurses and social workers. Other professionals were involved in the negotiation of professional boundaries too, for example physiotherapists, occupational therapists, care workers. However, the main bone of contention was between nurses and social workers. Paperwork was at the centre of the rivalry, but also provided a way to solve, or at least work around, conflict. 
Paperwork has been a long-standing boundary-marker between the two professions (Huby and Rees 2005), particularly following the introduction of care management by the reforms of community care described above. Social workers lost a key dimension of their role through that reform. Social work once emphasised community work and one-to-one long-term support in which paperwork was an element, for example in arranging benefits or housing. With the introduction of care management, 'doing the paperwork' became the main task. Moreover, their position was under threat because other professionals, for example nurses or occupational therapists or physiotherapists, can take on the work of care managers and add a dimension to existing responsibilities, such as medication (nurses), physical mobility (physiotherapists) and aids to daily life (occupational therapists). Social workers, however, no longer had a well understood dimension to their work besides the paperwork.

This tension and contest are evident in our material. It has several aspects, all revolving around paperwork. On the one hand, social workers resisted the stereotype as the 'ones who fill in the forms', whilst, on the other, they were unhappy when nurses took over because their role was felt to be usurped by others. A senior social worker in a Scottish OP Team spoke for a number of his social work colleagues:

And I think we're in a difficult position, in terms of health for instance - our skills are not valued by our colleagues, who see themselves as being able to do anything that we can do. And in fact, nurses are coming into care management and because they're completing care management tasks, they see that as 'well, we're doing social work' because they don't see the difference, they don't understand the difference.

A nursing care manager from another OP Team in Scotland countered:

One of the bones of contention that we had was things like claiming benefits, because I don't know if you've seen benefit forms, but they can be 50 pages long and they're very repetitive and boring to fill in. But traditionally it wasn't a nurse's role to do that. We passed them to social work because they were the experts in getting these things in properly. Now, it's something that we do ourselves because we're the ones that tend to know our clients. Housing issues, family issues, all that kind of thing, we deal with, as nursing case managers as well.

The negotiations and disputes about completing the paperwork were, however, important in helping staff from different backgrounds understand each other's roles and how to work together, even if rivalries were not necessarily resolved. 
Social workers often taught their NHS colleagues how to complete the paperwork for benefits and care management and thus helped them with this practical task and so also demonstrated what 'doing the paperwork' entailed in terms of relationship work with vulnerable people.

The paperwork, the work of completing the forms and interpreting the information they contained, became instrumental in building and deepening relationships and creating a joint understanding about the day-to-day care work and how to get around the tensions the work entailed. The paperwork provided a focus for this conversation, but it was not the main ingredient. There had to be an ongoing conversation of which the paperwork could become a part, and this conversation and the shared understanding was the product of working together for a long time. It was all about 'the soft stuff' as a Nurse Manager from an England OP Team explained:

It's part of what I call the 'soft stuff', that's what comes out from working with each other. And you overhear conversations, and you hear how people think and it changes your mind about how people are, much more than a formal meeting or a phone call.

A case in point is the Single Shared Assessment, which is a form that any member of the team who sees a client first should complete, thus doing away with many care professionals, each with separate assessment forms, asking a vulnerable person the same questions in slightly different ways. This form only worked if it became an integrated part of the process through which team members knew each other and the way they worked and thus shared a language and understanding. If the relationships were not there then the single shared assessment became a piece of 'bloody paperwork' without a function, as a social worker in an OP team in a city in Scotland explained:

But I think that certainly single shared assessment became
about the paperwork and not about the process, because you
can't argue with the idea behind single shared assessment, you
know, you... it makes perfect sense. But the paperwork issue
was seen to have been imposed by Social Work and people
who probably would have picked up the phone and just had
discussions in the past were scared to do it because they'd
have to follow it on with 40 pages of paper!

Paperwork also played a central role in mediating the relationships between individual workers and shifting and often opaque organisational frameworks. Moving away from the operational 'coal face' and upwards through the management structures the conversations of which paperwork became a part were increasingly removed from the contexts and the process in which the paperwork 


\section{Guro Huby Ẽ John Harries - Bloody Paperwork}

was produced. The conversations became about the data, as products of the work, rather than the work and process of its production.

The role of managers illustrates this changing role of paperwork. They had a dual role of oversight and support, and these two aspects of their role sometimes proved to be at odds with each other. On the one hand, managers we spoke to were close to the operational work in the teams, were aware of the distorting effects paperwork could have on the care work and tried to mediate between the two, as illustrated by this exchange between a manager of an English CMHT and one of the authors of this paper:

Manager: I suppose that's one of the advantages of the service managers' operational meetings, is finding ways of managing the targets with the least additional work as possible really. I don't mean not doing the work that's required but ...

Interviewer: ... but in some ways don't start making that work just to create evidence.

M: No to tick boxes for the targets, but actually to make sure that the real work is being done. I have quite a systematic approach. So, wherever you can build in joint ways of evidencing some of these things without creating additional work, that's what we're aiming to do really. And at that point, people aren't then focused so much on the kind of tick-box performance aspect of it.

On the other hand, managers 'looked upwards' and were accountable for the cost, safety and quality of services they managed. The paperwork mediated this accountability in ways that placed managers squarely at the nexus of the different realities of care work, as a manager of a CMHT in England explained:

So, we have loads of performance indicators, and generally we don't have much movement in them, any sort of. We can't, we don't generally say well we want to do this. We want to be innovative and have our own particularly... That's something that doesn't happen very often these days. But no, but it's just about improving standards of care and quality.

And at times the paperwork could rebound on managers and usurp their efforts at mediating between the different realities of the work. For example, the 'naughty girls and boys lists' Janet described in relation to the CPA was produced 'by the CPA' for each team and the manager's job was to distribute the lists to his or her team. 
The work managers did to facilitate 'real work' was, moreover, often undone by the instability of the system in which they worked. One manager had worked for three years putting in place a training programme to make the social care staff in his integrated service qualified to share the work of handing out medication, a job only nurses could do because they had the necessary clinical training, only for this work to unravel through a restructuring of the Primary Care Trust in which his service was located.

\section{Conclusion}

A central problematic of algorithmic governance in the integrated settings we studied has appeared from our discussions: Are the members of the health and social care teams we spoke to, as producers of the paperwork that alienated both themselves and their users from the reality of day-to-day provision of care, implicated in their own suppression? Or are they, and their paperwork, active participants in changing the evolving landscape of care? Or are they both, and what does that mean?

This problematic has emerged from our examination of workers' descriptions of the paperwork they do from two perspectives, grounded in two scholarly traditions. Seen from the perspective of writers describing the increasingly totalising function of bureaucratic tools of administration and oversight, paperwork appears as an alienating force produced by workers themselves. Their translations of the minutiae of their everyday care work into data become an agent for the increasingly stringent control of everyday care work, and workers end up in a Foucauldian nightmare, governing themselves by their own work. Seen from the perspective of ANT, paperwork can become central to negotiations about how best to coordinate the care for people with complex problems. Workers and managers in these conversations were working to shape the conditions of their work, and paperwork was an active participant, albeit in different ways depending on the level of the organisation and the context of the conversations. The point of our analysis is not to assess which of these perspectives are 'right', but to suggest that paperwork could be both, depending on context. We suggest that the alienating effect of paperwork was a product of the context in which it operated, rather than innate properties of the process of governance itself. When paperwork became the centre of action and conversation in settings cut-off from the work where the paperwork was done, it was the product of the work, the data, which became the focus. The further away from the work of datafication, the greater the likelihood that paperwork could revert to a 'thing': the product of care-workers efforts yet acting as something outside those efforts, both misrepresenting and controlling the work of caring for the elderly and those with mental illnesses. Workers and their managers worked hard to create settings where the paperwork was part of, and connected to, the issues of day-to-day care delivery and so an integral part of the networks of people and things, forms and computers, that organised and delivered the care. However, the system all too often unzipped, and the networks fragmented, leaving the paperwork, the CPA, the SSA, the SAP and 
the PIMS, to do their thing unchecked by and unrelated to, the messy reality of care work with people living complicated lives.

The main message from our work is that for the ideals of Digital Era Governance in integrated health and social care to be brought to fruition we have to start bottom up with the painstaking organisation of networks of staff and managers working across sectors and services into stable networks centred around formal and informal collaborative work. The introduction of digital tools of governance, no matter how sophisticated, will not paper-over the cracks; rather, unless the paperwork is a part of networks that are stable and long-acting enough for the 'soft stuff' of working together to be securely established the digital tools will disrupt the network-building that is vital for the Digital Era Governance dream to come true. Yet, the longevity and stability of networks is precisely the problem in integrated care because of an inherent instability of the policy process (Huby, Cook and Kirchoff 2018).

We imply that paperwork can be imagined as a coin that keeps flipping between paperwork as alienating and paperwork as facilitating, without venturing to predict which side will be up or when or if the coin finally lands. It is all in the making. We also suggest that this analysis of paperwork as at the same time alienating and a spur to innovative practice may have transfer value to other settings. Health and social care staff and managers are not alone in finding themselves at the butt of more or less distorted interpretations of data they themselves have produced and returned. Anthropologists share the experience to the full. This experience can mobilise creativity in responses that also contributes to development of the discipline in altered institutional frameworks (Strathern 2000, 295).

\section{Author Bios}

Dr Guro Huby is a social anthropologist and professor of health services research at the University College Østfold, Norway. She completed her $\mathrm{PhD}$ in social anthropology on coordination of services for people with HIV/AIDS in Lothian, Scotland, in 1997. She then worked for 13 years at the University of Edinburgh in the field of practice-related research and development of health services, with a particular focus on integration of health and social care in Scotland. Application of anthropological perspectives and theory to the practice and politics of health and health services has been central to her work and publications. Since 2013 she has held part time appointments at the University College Ostfold and is now affiliated with the MA programme Psychosocial work. Contact: Guro.O.Huby@hiof.no

Dr Fohn Harries is a now more-than-senior (title pending) teaching fellow in Social Anthropology at the University of Edinburgh. His work has included research concerning the politics of memory in postcolonial settler societies, with an emphasis on expressions of settler nativism in Newfoundland, Canada, and contributions to collaborative research concerning the articulation of care roles in 
integrated health and social care teams in the UK. The later study has given rise to a more general interest in the managerial culture of public service organisations and the contributions of anthropological approaches to better understandings of that culture.

\section{Acknowledgements/Funding}

We thank the health and social care staff who took time away from their (paper)work to contribute expertise and knowledge to the study! A special thanks to our colleagues Dr Eddie Donaghy and Dr Pamela Warner, both University of Edinburgh, for their collaboration. The study was funded by a Department of Health Policy Research Programme, social Care workforce Research Initiative, grant no 035/0087.

\section{References}

Bevir Mark. 2008. Key Concepts in Governance. London: Sage.

Cook, Ailsa and John Harries. 2014. "Zipping up or zipping down: reflections on integration at the front line." Journal of Integrated Care 22, no. 3. https:// doi.org/10.1108/JICA-02-2014-0007

Du Gay, Paul. 2000. In Praise of Bureaucracy. London: Sage.

Du Gay, Paul. 2005. The Values of Bureaucracy: An Introduction. In The Values of Bureaucracy, edited by Paul Du Gay, 1-16. Oxford: Oxford University Press.

Dunleavy, Patrick, Helen Margetts, Simon Bastow, and Jane Tinkler. 2006. "New Public Management is Dead - Long Live Digital-era Governance." Fournal of Public Administration Research and Theory 16, no. 3: 467-494. https:// doi.org/10.1080/09540969409387823

Dunleavy, Patrick, and Christopher Hood. 1994. "From Old Public Administration to New Public Management." Public Money \& Management 14, no. 3: 9-16. https://doi.org/10.1080/09540969409387823

Erikson, Kai. 1986. “On Work and Alienation.” American Sociological Review 51, no. 1: 1-8. https://doi.org/10.2307/2095474

Felski, Rita. 2011. “Context Stinks!” New Literary History 42, no. 4: 573-591. https://doi.org/10.1353/nlh.2011.0045

Glasby, Jon. 2006. "Bringing Down the Berlin Wall: Partnership Working and the Health and Social Care Divide." Health E' Social Care in the Community, 14, no. 3: 195-196. https://doi.org/10.1111/j.1365-2524.2006.00626.x 
Guro Huby E Fohn Harries - Bloody Paperwork

Glasby, Jon. 2017. "The Holy Grail of Health and Social Care Integration." BMF 356, no. j801. https://doi.org/10.1136/bmj.j801

Goodwin, Nick and Simon Lawton-Smith. 2010. "Integrating Care for People with Mental Illness: The Care Programme Approach in England and its Implications for Long-term Conditions Management." International journal of integrated care, 10, no. 1. https://doi.org/10.5334/ijic.516

Gov.UK. 2014. "Delivering Better Integrated Care.” Accessed October 6, 2020. https://www.gov.uk/guidance/enabling-integrated-care-in-the-nhs.

Graeber, David. 2012. "Dead Zones of the Imagination: On Violence, Bureaucracy, and Interpretive Labor: The Malinowski Memorial Lecture." HAU: journal of Ethnographic Theory 2, no. 2: 105-128. https://doi.org/ $\underline{10.14318 / \text { hau2.2.007 }}$

Graeber, David. 2015. The Utopia of Rules: On Technology, Stupidity, and the Secret Foys of Bureaucracy. London: Melville House.

Griffiths, Roy. 1988. Community Care: Agenda for Action: A Report to the Secretary of State for Social Services by Sir Roy Griffiths. HM Stationery Office.

Hood, Christopher. 1991. "A Public Management for All Seasons?” Public Administration 69, no. 1: 3-19. https://doi.org/10.1111/ j.1467-9299.1991.tb00779.x

Hood, Christopher. 1995. "The "New Public Management" in the 1980s: Variations on a Theme." Accounting, Organizations and Society 20, no. 2: 93109. https://doi.org/10.1016/0361-3682(93)E0001-W

Hornborg, Alf. 2014. "Technology as Fetish: Marx, Latour, and the Cultural Foundations of Capitalism." Theory, Culture E̊ Society 31, no. 4: 119-140. https://doi.org/10.1177/0263276413488960

Huby, Guro, Ailsa Cook and Ralf Kirchoff. 2018. "Can We Mandate Partnership Working? Top Down Meets Bottom Up in Structural Reforms in Scotland and Norway." Fournal of Integrated Care 22, no. 2: 109-119. https://doi.org/ $\underline{\text { 10.1108/JICA-11-2017-0041 }}$

Huby, Guro, and Gwyneth Rees. 2005. "The Effectiveness of Quality Improvement Tools: Joint Working in Integrated Community Teams." International Fournal for Quality in Health Care 17, no. 1: 53-58. https://doi.org/10.1093/intqhc/mzi003

Huby, Guro et al. 2010. "Supporting the Reconfiguration of Social Care Roles in Integrated Settings in the UK: A Comparative Study Across Three Health and Social Care Economies.” Edinburgh and Swansea: The University of 
Guro Huby E Fohn Harries - Bloody Paperwork

Edinburgh and Swansea University. Accessed 6 October, 2020. https:// www.kcl.ac.uk/scwru/res/hrp/hrp-studies/hearth/dhinitiative/projects/ hubyetal2010recon.pdf

Iliffe, Steve and Jill Manthorpe. 2019. The Unexpected Return of Alienation: Job Dissatisfaction, 'Burnout' and Work Estrangement in the NHS. Renewal: A Journal of Labour Politics 27, no. 4: 50-59. https://doi.org/ $\underline{10.1177 / 0141076819855956}$

Kafka, Ben. 2009. "Paperwork: The State of the Discipline." Book History 12, no. 1: 340-353. https://doi.org/10.1353/bh.0.0024

Kalpokas, Ignas. 2019. Algorithmic Governance: Politics and Law in the Post-human Era. Cham, Switzerland: Springer Nature. https://doi.org/ $\underline{10.1007 / 978-3-030-31922-9}$

Kartal, Nazan. 2018. "Evaluating the Relationship Between Work Engagement, Work Alienation and Work Performance of Healthcare Professionals." International fournal of Healthcare Management 11, no. 3: 251-259. https:// doi.org/10.1080/20479700.2018.1453969

Katzenbach, Christian, and Lena Ulbricht. 2019. "Algorithmic Governance." Internet Policy Review 8, no. 4: 1-18. https://doi.org/ $\underline{10.14763 / 2019.4 .1424}$

Kingdon, David. 1994. "Care Programme Approach: Recent Government Policy and Legislation." Psychiatric Bulletin 18, no. 2: 68-70. https://doi.org/ $\underline{10.1192 / \mathrm{pb} .18 .2 .68}$

König, Pascal. 2020. "Dissecting the Algorithmic Leviathan: On the Sociopolitical Anatomy of Algorithmic Governance." Philosophy E Technology 33, no. 3: 467-485. https://doi.org/10.1007/s13347-019-00363-w

Latour, Bruno. 2004. "Why Has Critique Run Out of Steam? From Matters of Fact to Matters of Concern." Critical Inquiry 30, no. 2: 225-248. https:// doi.org/10.1086/421123

Latour, Bruno. 2007. Reassembling the Social: An introduction to Actor-Network-Theory. Oxford: Oxford University Press.

Le Grand, Julian. 2003. Motivation, Agency, and Public Policy: Of Knights and Knaves, Pawns and Queens, Oxford: Oxford University Press. https://doi.org/ $\underline{10.1093 / 0199266999.001 .0001}$

Margetts, Helen, and Patrick Dunleavy. 2013. "The Second Wave of Digital-era Governance: A Quasi-paradigm for Government on the Web.” Philosophical 
Guro Huby E Fohn Harries - Bloody Paperwork

Transactions of the Royal Society A: Mathematical, Physical and Engineering Sciences 371, no. 1987: 1-17. https://doi.org/10.1098/rsta.2012.0382

Marx, Karl. 1983. "From the First Manuscript: Alienated Labour." In The Portable Karl Marx, selected and edited by Eugene Kamenka, 131-146. New York: Penguin. Originally published in Marx-Engels-Gesamtausgabe (Moscow: Marx-Engels Institute, 1932).

McLaughlin, Kate, Stephen Osborne and Ewan Ferlie. 2002. New Public Management: Current Trends and Future Prospects. London and New York: Routledge.

Mejias, Ulises A., and Nick Couldry. 2019. "Datafication." Internet Policy Review 8, no.4. https://doi.org/10.14763/2019.4.1428

Mayer-Schönberger, Viktor and Kenneth Cukier. 2017. Big Data: The Essential Guide to Work, Life and Learning in the Age of Insight. London: John Murray.

Nancarrow, Susan and Alan Borthwick. 2005. "Dynamic Professional Boundaries in the Healthcare Workforce." Sociology of Health E Illness 27, no.7:

897-919. https://doi.org/10.1111/j.1467-9566.2005.00463.x

Noys, Benjamin. 2014. "The Discrete Charm of Bruno Latour." In (Mis)readings of Marx in Continental Philosophy, edited by Jernej Habjan and Jessica Whyte, 195-208. New York: Palgrave Macmillan. https://doi.org/ $\underline{10.1057 / 9781137352835 \quad 13}$

Orlikowski, Wanda. 2007. "Sociomaterial Practices: Exploring Technology at Work." Organization Studies 28, no. 9: 1435-448. https://doi.org/ $\underline{10.1177 / 0170840607081138}$

Osborne, David and Ted Gaebler. 1992. Reinventing Government: How the Entrepreneurial Spirit is Transforming the Public Sector. New York: AddisonWesley.

Osborne, Stephen. 2010. "Introduction: The (New) Public Governance: A Suitable Case for Treatment?" In The New Public Governance?, edited by Stephen Osborne, 1-17. London: Routledge. https://doi.org/ $\underline{10.4324 / 9780203861684}$

Özer, Özlem, Özgür Uğurluoğlu, Meltem Saygıll, and Cuma Sonğur. 2019. “The Impact of Work Alienation on Organizational Health: A Field Study in Health Sector." International Fournal of Healthcare Management 12, no. 1: 18-24. https://doi.org/10.1080/20479700.2017.1312804 
Guro Huby Ẽ John Harries - Bloody Paperwork

Pearlin, Leonard, 1962. "Alienation from Work: A Study of Nursing Personnel." American Sociological Review 27, no. 3: 314-326. https://doi.org/ $\underline{10.2307 / 2089793}$

Power, Michael. 1997. The Audit Society: Rituals of Verification. Oxford: Oxford University Press.

Power, Michael. 2003. "Evaluating the Audit Explosion." Law \& Policy 25, no. 3: 185-202. https://doi.org/10.1111/j.1467-9930.2003.00147.x

Quinlan, Elizabeth. 2009. “The 'Actualities' of Knowledge Work: An Institutional Ethnography of Multi-disciplinary Primary Health Care Teams." Sociology of Health E Illness 31, no. 5: 625-641. https://doi.org/10.1111/ j.1467-9566.2009.01167.x

Rhodes, R. A. 1994. "The Hollowing Out of the State: The Changing Nature of the Public Service in Britain." The Political Quarterly 65, no. 2: 138-151. https://doi.org/10.1111/j.1467-923X.1994.tb00441.x

Sayes, Edwin. 2017. "Marx and the Critique of Actor-Network Theory: Mediation, Translation, and Explanation." Distinktion: Journal of Social Theory 18, no. 3: 294-313. https://doi.org/ 10.1080/1600910X.2017.1390481

Seaver, Nick. "Algorithms as culture: Some tactics for the ethnography of algorithmic systems." Big Data E् Society 4, no. 2 (2017) https://doi.org/ $\underline{10.1177 \% 2 F 2053951717738104}$

Shore, Chris, and Susan Wright. 1999. "Audit Culture and Anthropology: Neoliberalism in British Higher Education." Fournal of the Royal Anthropological Institute 5, no. 4: 557-575. https://doi.org/10.2307/2661148

Shore, Cris, and Susan Wright. 2015. "Governing by Numbers: Audit Culture, Rankings and the New World Order." Social Anthropology 23, no. 1: 22-28. https://doi.org/10.1111/1469-8676.12098

Simpson, Alan, Carolyn Miller \& Len Bowers. 2003. "The History of the Care Programme Approach in England: Where Did It Go Wrong?" Journal of Mental Health 12, no. 5: 489-504. https://doi.org/ $\underline{10.1080 / 09638230310001603555}$

Strathern, Marilyn. 1996. "From Improvement to Enhancement: An Anthropological Comment on the Audit Culture." Cambridge Anthropology 19, no. 3: 1-21. 
Guro Huby E Fohn Harries - Bloody Paperwork

Strathern, Marilyn. 2000 Afterword: accountability....and ethnography. In Audit Cultures: Anthropological studies in accountability, ethics, and the academy. edited by Marilyn Strathern, 279 - 304. London and New York: Routledge.

Timmermans, Stefan, and Rene Almeling. 2009. "Objectification, Standardization, and Commodification in Health Care: A Conceptual Readjustment." Social Science \& Medicine 69, no. 1: 21-27. https://doi.org/ $\underline{10.1016 / j . s o c s c i m e d .2009 .04 .020}$

Tsoukas, Haridimos. 1997. "The Tyranny of Light: The Temptations and the Paradoxes of the Information Society.” Futures 29, no. 9: 827-843. https:// doi.org/10.1016/S0016-3287(97)00035-9

White, Hylton. 2013. "Materiality, Form, and context: Marx contra Latour." Victorian Studies 55(4): 667-682. https://doi.org/10.2979/ victorianstudies.55.4.667

Whittle, Andrea, and André Spicer. 2008. "Is Actor Network Theory Critique?" Organization Studies 29, no.4: 611-629. https://doi.org/ $\underline{10.1177 / 0170840607082223}$

Woods, Kevin. 2001. "The Development of Integrated Health Care Models in Scotland." International Fournal of Integrated Care 1, no. 2. http://doi.org/ $\underline{10.5334 / \text { ijic. } 29}$

Ysa, Tamyko, Adrià Albareda and Sarah Forberger. 2014. "What is Governance?" In Reframing the Science and Policy of Nicotine, Illegal Drugs and Alcohol - Conclusions of the ALICE RAP Project, edited by Peter Anderson et al., 8-17. The ALICE RAP project, http://www.alicerap.eu/ 